\title{
高温高圧下における硫化カドミウムの電気伝導度*
}

\author{
大杉治 郎** 清 水澄*** \\ 中村登紀男*** 小野寺昭史***
}

\section{Electrical Conductivity of Cadmium Sulfide under High Pressure and High Temperature}

by

\author{
Jiro Osugi, Kiyoshi Shimizu, Tokio Nakamura and Akifumi Onodera \\ (Faculty of Science, Kyoto University, Kyoto)
}

The electrical resistance of a single crystal of cadmium sulfide was measured at pressures up to $40 \mathrm{kbar}$ and at temperatures up to $700^{\circ} \mathrm{C}$ in a cubic compact anvil high pressure apparatus.

The electrical conductivity of GdS of either the atmospheric wurtzite phase or the high-pressure rock salt phase is semiconductive. In the high-resistivity samples used in the present experiment the electrical resistance increased with pressure in either phases, the wurtzite or the rock salt. From the measurements of electrical resistance as a function of temperature, it is found that a band gap of GdS of the wurtzite phase is about $2.5 \mathrm{eV}$. For the GdS of the rock salt phase a band gap of about $0.8 \mathrm{eV}$ is obtained.

(Received Aug. 17, 1967)

\section{1 緒言}

周期律表のIV族元素，III-V族化合物，II-VI族化合 物は, $\mathrm{Ge}, \mathrm{Si}, \mathrm{InSb}, \mathrm{GdS}, \mathrm{GdTe}$ などをはじめとして， その半導体的特性のために注目を受けてきた。 てれら の半導体の高圧下における電気的性質の研究は, 価電 子帯の極大と伝導帯の極小との間のエネルギギャップ の圧力効果という立場から伝導機構の解明に寄与して きた。

硫化カドミウムについては, 高圧下での電気的性臀 および光学的性質の研究が行なわれたが，それらはい ずれも室温におけるものである。高温高圧下におけ る CdS の電気的性質の研究は, Samara らの $250^{\circ} \mathrm{C}$ のみにおける実駚以外はなされていない.

本研究は, 単結晶の $\mathrm{CdS}$ の電気伝導度を最高 $700^{\circ} \mathrm{C}$ までの高温, 最高 40kbar までの高圧下で測定を行な ったものである。ウルッァイト相と岩塩相における電 気伝導度の温度効果の測定からエネルギギャップを求 めた。

\section{2 実験}

GdS 試料は溶融法によって生長させた高純度の単

* 本報を「高圧下における無機半導体の電気伝導度に関する研究 (第1報)」(Electrical Conductivity of Inorganic Semiconductors under High Pressure, I) とする 原稿受理 昭和 42 年 8 月 17 日

** 正 会 員 京都大学理学部 京都市左京区北白川追分町

*** 京都大学理学部 京都少左京区北白川追分町

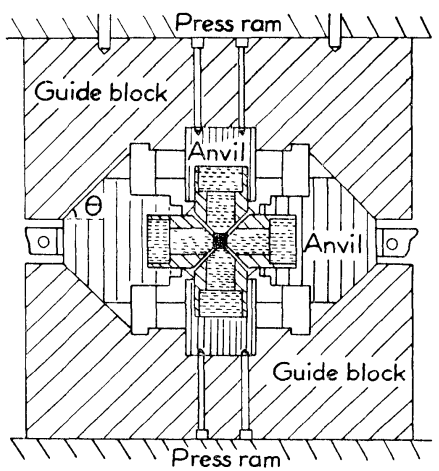

Fig. 1. Vertical cross section of compact cubic anvil apparatus.

結晶から切り出して用いた。

実験は Fig. 1 亿示す六面体アンビル型高压装置にお いて行なった，装置の原理，操作についてはすでに報 告したので，乙てでは簡単な記述にとどめる. 圧力較 正はビスマス, タリウム，バリウム試料の相転移を起 てさせるのに要する, ラムへのオイル压力を求めるて とによって行なった。これらの試料の転移は電気抵抗 測定によって追跡した。 圧力較正点は $\mathrm{Bi}_{\mathrm{I}-\mathrm{II}}$ の 25.4 の kbar, $\mathrm{Tl}_{\mathrm{II}-\mathrm{III}}$ の $37.0 \mathrm{kbar}, \mathrm{Ba}_{\mathrm{I}-\mathrm{II}} 59 \mathrm{kbar}, \mathrm{Bi}_{\mathrm{V}-\mathrm{VI}}$ の $89 \mathrm{kbar}$ である。 $25.4 \mathrm{kbar}$ 以上では直線関係がみ られる。 $25.4 \mathrm{kbar}$ 以下の圧力の較正には水銀の凝固 


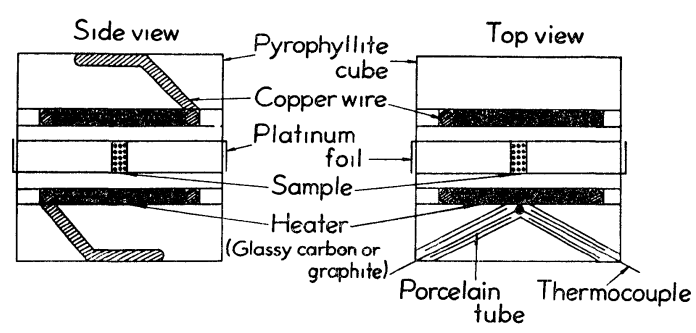

Fig. 2. Sample configurations for resistance measurements in cubic anvil apparatus.

点を用いた。 $25.4 \mathrm{kbar}\left(\mathrm{Bi}_{\text {I-II }}\right), 11 \mathrm{kbar}$ (室温におけ る水銀の凝固), 零の間に直線が描かれる。室温におけ る圧力較正值を高温においても用いた，与えられた压 力の精度は， $25 \mathrm{kbar}$ 以下では $\pm 1.4 \mathrm{kbar}, 25 \mathrm{kbar}$ 以 上では $\pm 1.0 \mathrm{kbar}$ である。

電気抵抗測定に用いた試料体の配置はさきに報告し たものと同様である。 その概略を Fig. 2 亿示す. パイ ロフィライトが試料保持体および圧力媒体となってお り, 一稜の長さは $13 \mathrm{~mm}$ である. 内部には直径 6 mmのグラッシィ・カーボンがはいっており，てれに 通電用の銅線が接している. グラッシィ・カーボンヒ 一タの内部には $4 \mathrm{~mm}$ のパイロフィライトの筒と, 直 径 $2 \mathrm{~mm}$ のパイロフィライト棒と電極用の白金はくが

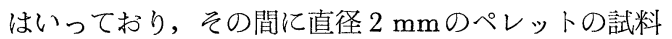
がある６個のアンビルによる試料体の圧縮によりペ レットに静水圧的な压力が加わる。ヒータの外壁に熱 電対が接触するように置き，アンビル間のガスケット から取り出して温度を測定した。

六つのアンビルはテフロンシートによって電気的に 絶縁されている。二つのアンビルを通電用として用い, 他の二つのアンビルを電気抵抗測定用の電極として用 いた．試料の加熱は銅線を経て，グラッシィ・カーボ ンに大電流を通ずることによって行なった。

温度測定には, 直径 $0.3 \mathrm{~mm}$ のクロメルーアルメル または白金一白金ロジウム（10\%）の熱電対を用いた. クロメルーアルメル熱電対ではスズ，鉛，覀鉛および アルミニウムの融点を用いて較正を行なった．白金一 白金ロジウム $(10 \%)$ の熱電対の場合は, 温度は数值 表から読みとった。 熱電対の起電力に及ぼす压力の影 響に対して，Hanneman と Strong の測定値により 補正を行なった。

エネルギギャップは一定圧力の条件で電気伝導度の 温度依存性の測定から求めた。昇温の際は抵抗值が安 定するまでその温度に保持した (10分〜 2 時間). また， 一定温度において電気抵抗の圧力による変化を測定し た. 圧力はそれぞれの点で抵抗值が安定するまで保持 した (10分〜 1 時間).

抵抗值と実験終了後の試料の大きさの測定から比抵
抗を計算できるが，試料回収の際に粉研することが多 く，試料の大きさの測定が不可能となった．とのため 測定値は抵抗值で記してある。

\section{3 結果および考察}

\section{$3 \cdot 1$ エネルギギャップ}

CdS は常圧のウルツァイト相においても高压の岩 塩相においても半導体である. 固有伝導領域ではその 抵抗值 $R$ は次式で与えられる。

$$
R=R_{\infty} \exp \left(E_{g} / 2 k T\right)
$$

ここで $E_{g}$ は伝導带の極小と洒電子带の極大との間の エネルギギャップ，k はボルツマン定数， $T$ は絶対温 度， $R_{\infty}$ は温度に無関係な定数である。したがって $\log R$ を $(1 / T)$ に対してプロットして得られる直線部 の傾きからエネルギギャップが求められる. Fig. 3 亿

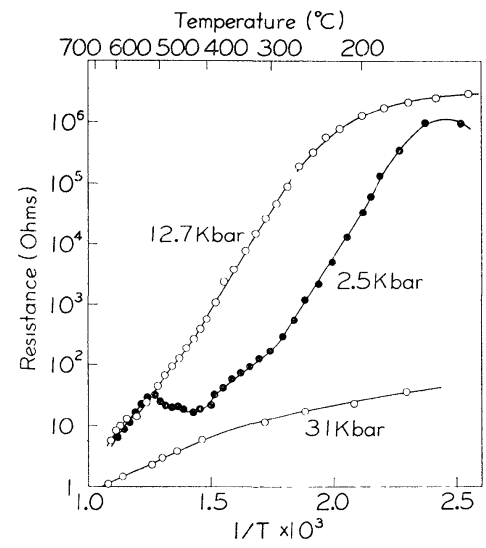

Fig. 3. Resistance vs. 1/T isobars.

は三つの圧力における測定結果が示してある。ウルツ アイト相とついては $2.5 \mathrm{kbar}$ で $E_{g}=2.48 \mathrm{eV}, 12.7$ $\mathrm{kbar}$ で $2.52 \mathrm{eV}$ という值が求められる。 $E_{g}$ は压力 によって増加し，その割合は

$$
d E_{g} / d p=4.0 \times 10^{-6} \mathrm{eV} / \mathrm{bar}
$$

である。

本実験で求められたウルツァイト相のエネルギギャ ップの值は高圧下での光学测定によって求められた值 $\simeq 2.5 \mathrm{eV}$ と一致をみる. Gutsche は $12000 \mathrm{~atm}(12.2$ kbar) までの静水圧力下で， GdSの単結晶の c 軸に平 行な方向と垂直な方向で光学吸収の測定を行なった。 それによると，

$$
\begin{aligned}
& d E_{g} \perp c / d p=4.4 \pm 0.3 \times 10^{-6} \mathrm{eV} / \mathrm{bar} \\
& d E_{g} / / C / d p=3.9 \pm 0.3 \times 10^{-6} \mathrm{eV} / \mathrm{bar}
\end{aligned}
$$

である. Glyamov らも静水圧力下での実験を行ない, $E_{g}$ の圧力とう配を， $4.5 \sim 4.6 \times 10^{-6} \mathrm{eV} / \mathrm{bar}$ と報告し た. 本実験における $E_{g}$ の圧力による増加は，乙れま での光学測定による報告值とかなりよく一致している。 
Hopfield 年はウルッォイト形の CdS の伝導带の極 小と価電子带の極大はともに， Brillouin 帯の中心に あるととを示した。 しかし， Gardona 用いて，価電子带の極大は Brillouin 带の中心にない ことを示している.

圧力は原子間距離を短縮させるととによって, 波動 関数を広げ，乙の結果洒電子带と伝導帯のギャップを 小さくするととが期待されるのであるが CdS におい ては上記のように压力によって大きくなる。常圧にお いて GdS は ZnSe と任意の割合で固溶体を形成し, ZnSe の割合か増加すると，格子定数は， $c, a$ ともに 減少する. エネルギギャップは室温で CdS では 2.5 $\mathrm{eV}, \mathrm{ZnSe}$ では $2.57 \mathrm{eV}$ であって, 固溶体ではてれら の中間の值を示す．とのととから CdS そ ZnSe を加 えるととと，圧力を加えるととの間にはある類似性が 存在すると考えられる。したがって, 圧力増加に伴う 原子間距離の減少により CdS のエネルギギャップの 増加が予想される。

II-VI族半導体，特に CdS, GdSe, CdTe は類似し た物理的性質を有することから，その带構造も類似し ているものと考えられ，その結果エネルギギャップに 対する圧力の効果も同様であると思われる.

岩塩相については, Fig. 3 のデータより, $31 \mathrm{kbar}$ $\boldsymbol{E}_{g}=0.78 \mathrm{eV}$ が求められる. Drickamer らは光学測定 により $E_{g}=1.7 \mathrm{eV}, d E_{g} / d p=0$ なる值を報告した。 Samara らは, $E_{g}=1.3 \mathrm{eV}, d E_{g} / d p=1.6 \times 10^{-6} \mathrm{eV} / \mathrm{bar}$ る值を報告した，とれらの差暴は，Samara らが述べ ているように岩塩相では試料が多結晶となっているた めかもしれない. 岩塩相の領或である高い圧力下では 熱電刘の短絡, 切断等のため実験は困難であった.

エネルギギャップの圧力依存性を温度依存性と比較 することは興味深いととである. ウルツァイト形の CdS の温度依存性の報告は多くみられる，波長に対 する吸収の依存性の測定によると，吸収端は温度上昇 とともに長波長側へ，1 1 A $/ \operatorname{deg}$ の割合でシフトする. 光導電性の測定によっても，吸収端がおよそ $1 \AA / \mathrm{deg}$ で長波長側にシフトすることが示された。 Bube は波 長の関数として光導電性を測定して, GdS のエネルギ ギャップの温度依存性を求めた. 温度の上昇によって $E_{g}$ は減少し， $d E_{g} / d T=-5.2 \times 10^{-4} \mathrm{eV} / \mathrm{deg}$ である。 格子の膨張によるエネルギギャップの温度依存性は次 式から求められる.

$$
\left(\frac{d E_{g}}{d T}\right)_{d}=-\frac{\alpha}{\beta} \frac{d E_{g}}{d p}
$$

ここで $\beta$ は結晶の等温圧縮率， $\alpha$ は膨張係数である。 CdS そ対して $\alpha=1.70 \times 10^{-5} \mathrm{deg}^{-1}$, Samara らの結果 からの $\beta=1.82 \times 10^{-6} \mathrm{bar}^{-1}$, そして本実験の結果汃ら の $d E_{g} / d p=4.0 \times 10^{-6} \mathrm{eV} / \mathrm{bar}$ を用いると，

$$
\left(\frac{d E_{g}}{d T}\right)_{d}=-3.7 \times 10^{-5} \mathrm{eV} / \mathrm{deg}
$$

が得られる。乙れは，Bube が求めた值よりも一つオ ーダが小さい.

したがって，エネルギギャップの温度依存性を格 子の熱膨張のみからは説明するととができず, 電子格子の相互作用から生ずる温度依存性の項を含めて考 えることが必要である。CdSでは室温における電子の 散乱は縦波方向の光子との作用によって起てされる。 との電子と光子の相互作用によるエネルギギャップの 温度依存性については, 武藤と大山, Fan 亿よって独 立に示された。 Fan によると，

$$
\begin{aligned}
& \frac{d E_{g}}{d T}=-\frac{\pi\left(e e^{*}\right)^{2} \hbar^{1 / 2}}{a^{3} M \omega_{l}^{3 / 2}}\left[\left(\frac{2 m_{n}^{*}}{\hbar^{2}}\right)^{1 / 2}+\left(\frac{2 m_{p}^{*}}{\hbar^{2}}\right)^{1 / 2}\right] \\
& \left(\frac{1}{e^{\omega_{l / k T}}-1}+1\right)
\end{aligned}
$$

である. (3)式において, $e$ はイオンの電荷, $e^{*}$ はイオ ンの有效電荷, $\hbar$ は Planck の定数を $2 \pi$ で除したも の, $k$ は Boltzmann の定数, $a$ は最近接原子間距離, $M$ は換算質量, $\omega_{l}$ は縦波光子の振動数, $m_{n}{ }^{*}$ と $m_{p 1}{ }^{*}$ はそれぞれ電子とホールの有效質量である. Suchet よる $e^{*}=0.97 e$, Collins の報告から求められた值 $\omega_{l}=5.7 \times 10^{13} \mathrm{sec}^{-1}$, Hopfield と Thomas による $m_{n} *$ $=0.20 m_{e}$ および $m_{p}{ }^{*}=0.7 m_{e}$ を用いると, $298^{\circ} \mathrm{K}$ に おいて,

$$
\frac{d E_{g}}{d T}=-2.2 \times 10^{-4} \mathrm{eV} / \mathrm{deg}
$$

という值を得る。これは Bubeによって測定された值 と同じオーダである. 以上の考察から CdS のエネル ギギャップの温度依存性は, 主として電子一格子相互 作用から生ずるものと考えられ, 格子の熱膨張のみか らは説明できないてとを知った。

\section{$3 \cdot 2$ 電気抵 抗}

Fig. 4 に見られるように，一定温度ではウルツァイ 卜相においても岩塩相においても電気抵抗は圧力とと もに増加する，圧力は伝導带あるいは価電子带のキャ リヤ濃度の変化, そして易動度の変化を通して電気伝 導度に影響を与える. 固有半導体に対して, 伝導度 $\sigma$ は次式で与えられる。

$$
\sigma=e\left(n \mu_{n}+p \mu_{p}\right)
$$

ととで, $n, p$ は電子とホールの濃度, $\mu_{n}$ と $\mu_{p}$ は電 子とホールの易動度, $e$ は電荷である。電子とホール の濃度は

$$
n=p=2\left(2 \pi k T / h^{2}\right)^{3 / 2}\left(m_{n} m_{p}\right)^{4 / 3} \exp \left(-E_{g} / 2 k T\right)
$$

で与えられる. こてで, $m_{n}$ と $m_{p}$ は電子とホールの 有効質量である。したがって伝導度は

$$
\sigma=e\left(\mu_{n}+\mu_{p}\right) \cdot 2\left(2 \pi k T / h^{2}\right)^{3 / 2}\left(m_{n} m_{p}\right)^{3 / 4} \exp \left(-E_{g} / 2 k T\right)
$$




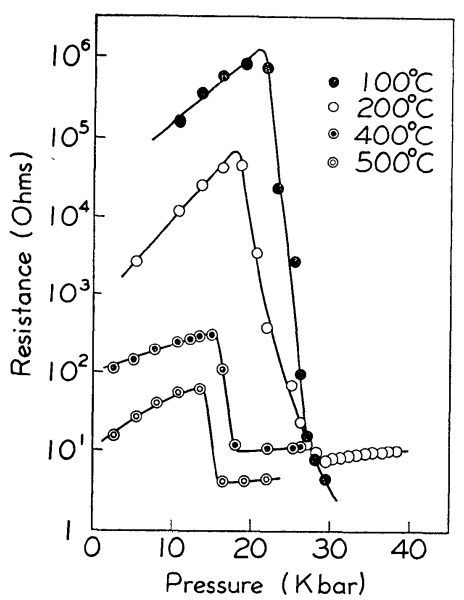

Fig. 4. Resistance vs. pressure isotherms.

となる. 比抵抗 $\rho$ は，次のようになる.

$$
\begin{aligned}
\rho & =\frac{1}{e\left(\mu_{n}+\mu_{p}\right)} \cdot \frac{1}{2 A} e^{E_{g} / 2 k T} \\
A & =\left(\frac{2 \pi k T}{h^{2}}\right)^{3 / 2}\left(m_{n} m_{p}\right)^{3 / 4}
\end{aligned}
$$

圧力による有効質量の変化は，圧力によるエネルギギ ヤップの変化と同じオーダで, ${ }^{1} 0^{-6} \mathrm{bar}^{-1}$ のオーダで ある．易動度の変化は散乱の機構に依存していて複

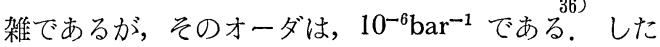
がって，伝導度に対して影響を与光る支配的な項は $E_{g}$ であると考えられる。(7)式を微分し，小さいオー ダの項を無視すると

$$
\frac{\partial \ln \rho}{\partial p}=\frac{1}{2 k T} \frac{\partial E_{g}}{\partial p}
$$

となる。一方，さきの(1)式で示される抵抗 $R$ は

$$
R=\rho \frac{l}{S}
$$

であるここで $l$ は試料の厚さ， $S$ は断面積である. 圧力による試料の大きさの変化を無視すると

$$
\frac{\partial \ln \rho}{\partial p}=\frac{\partial \ln R}{\partial p}
$$

いま，(10)式に従って Fig. 4 のウルツァイト相の抵抗

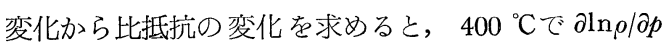
$=8.7 \times 10^{-5} \mathrm{bar}^{-1}$ となる. 一方(8)式で, 本実験で求め た $\partial E_{g} / \partial p=4.0 \times 10^{-6} \mathrm{eV} / \mathrm{bar}$ を用いて計算するると， $\partial \ln \rho / \partial p \approx 3.4 \times 10^{-5} \mathrm{bar}^{-1}$ となり, 実験值と比較的よく 一致している.

約 $200^{\circ} \mathrm{C}$ 以下では, 測定された伝導度は不純物伝導 に基づくものである，簡単なドナー・モデルにより

$$
\sigma=e \mu\left(N_{C} N_{D}\right)^{1 / 2} \exp \left(-\frac{E_{C}-E_{D}}{2 k T}\right)
$$

で与えられる. したがって

$$
\rho=\frac{1}{e \mu} \frac{1}{\left(N_{C} N_{D}\right)^{1 / 2}} \exp \left(\frac{E_{C}-E_{D}}{2 k T}\right)
$$

となる.とてで, $N_{C}=2\left(m^{*} k T / 2 \pi h^{2}\right)^{3 / 2}$ で, $N_{D}$ はドナ 一の濃度, $E_{C}-E_{D}$ はドナー準位のイオン化エネルギ である。(12)式より

$$
\frac{\partial \ln \rho}{\partial p}=-\frac{\partial \ln \mu}{\partial p}-\frac{3}{4} \frac{\partial \ln m^{*}}{\partial p}+\frac{1}{2 k T} \frac{\partial\left(E_{C}-E_{D}\right)}{\partial p}
$$

が与えられるが, 最初の 2 項は，さきに述べたように， $10^{-6}$ のオーダで, したがって $\partial \ln \rho / \partial p$ に比べて無視で きる. 水素様モデルによって，

$$
E_{C}-E_{D}=\frac{e^{4} m^{*}}{2 \hbar^{2} \varepsilon^{2}} \sim E_{g}{ }^{2}
$$

となる.乙こで $\varepsilon$ は透電定数である. この結果

$$
\frac{\partial\left(E_{C}-E_{D}\right)}{\partial p} \approx 2 \frac{\partial E_{g}}{\partial p}
$$

となるので

$$
\frac{\partial \ln \rho}{\partial p} \approx \frac{1}{k T} \frac{\partial E_{g}}{\partial p}
$$

が得られる。乙の式から $100^{\circ} \mathrm{C}$ における比抵抗変化の 計算 $1.2 \times 10^{-4} \mathrm{bar}^{-1}$ 值が求められる。 これは Fig. 4 から(10)式に基づいて求められた值 $\partial \ln \rho / \partial p=2.0 \times 10^{-4}$ $\mathrm{bar}^{-1}$ とよい一致をみる.

いずれの場合も, 電気抵抗の圧力による変化は， $E_{g}$ の圧力による変化によっていること示している.

岩塩相においては抵抗の增加の割合は非常に小さい. ての相では試料が多結晶となっているととと，エネル ギギャップの圧力変化の測定値が不足しているととか ら抵抗変化の説明は今後の検討を要する。

終わりに, 試料の提供をいただいた松下電器東京研 究所の大貫正実博士に感謝いたします.

\section{（昭和 40 年 10 月 21 日 第 7 回高圧討論会, 昭和 41 年 10 月 8 日 第 8} 回高圧討論会にて講演)

\section{参考 文 献}

1) Samara, G. A., and H.G. Drickamer, J. Phys. Ghem. Solids, 23, 357 (1962).

2) Böer, K.W., E. Gutsche, and E. Jahne, Phys. Status Solidi, 3, 922 (1963).

3) Edwards, A.L., T.E. Slykhouse, and H.G. Drickamer, J. Phys. Chem. Solids, 11, 140 (1959).

4) Edwards, A.L., and H.G. Drickamer, Phys. Rev., 122, 1149 (1961).

5) Gutsche, E., Naturwiss., 45, 486 (1958).

6) Gutsche, E., Phys. Status Solidi, 1, 719 (1961).

7) Samara, G. A., and A. A. Giardinı, Phys. Rev., 140, A388 (1965).

8) Osugi, J., K. Shimizu, K. Inoue, and K. Yasunami, Rev. Phys. Chem. Japan, 34, 1 (1964).

9) Bundy, F.P., "Modern Very High Pressure Techniques", R.H. Wentorf, Jr. ed., p. 19 (1962) 
Butterworths, London.

10) Klement, Jr., W., A. Jayaraman, and G.G. Kennedy, Phys. Rev., 131, 1 (1963).

11）大杉治郎, 清水澄, 中村登紀男, 小野寺昭史, 日化 誌, 88, 813 (1967).

12) Hanneman, R.E., and H. M. Strong, J. Appl. Phys., 36, 523 (1965) ; ibid., 37, 612 (1966).

13) Glyamov, K., N.A. Tikhomirova, and V.M. Fridkin, Fiz. Tverd. Tela, 7, 1037 (1966) ; English transl. : Soviet Phys.-Solid State, 7, 834 (1965).

14) Thomas, D.G., and J.J. Hopfield, Phys. Rev., 116, 573 (1959); Thomas, D.G., J.J. Hopfield, and H. Power, ibid., 119, 570 (1960); Hopfield, J.J., J. Appl. Phys., 32, 2277 (1961).

15) Gardona, M., J, Phys. Chem. Solids, 24, 1543 (1963).

16) Fischer, A.G., and R. J. Paff, J. Phys. Chem. Solids, 23, 1497 (1962).

17) Moss, T.S., "Optical Properties of Semi-conductors", p. 43 (1959) Butterworths, London.

18) Kröger, F.A., Physica, 7, 1 (1940).

19) Höhler, G., Ann. Physik, 4, 371 (1949).

20) Seiwert, R., Ann. Physik, 6, 241 (1949).

21) Radelt, H., Z. Naturforsch., 15a, 269 (1960).

22) Niekisch, E.E., Ann. Physik, 8, 291 (1951).

23) Caspary, R., and H. Müser, Z. Physik, 134, 101 (1952).

24) Bube, R.H., Phys. Rev., 98, 431 (1955).
25) “American Institute of Physics Handbook" 2nd ed., (1963) McGraw-Hill Book Co., Inc., New York.

26) Radkowsky, A., Phys. Rev., 73, 749 (1949).

27) Miyazawa, H., H. Maeda, and H. Tomishima, J. Phys. Soc. Japan. 14, 41 (1959).

28) Groth, R., and R. Memming, Phys. Status Solidi, 1, 650 (1961).

29) Muto, T., and S. Oyama, Progr. Theoret. Phys. (Kyoto), 5, 833 (1950).

30) Fan, H.Y., Phys. Rev., 82, 716 (1951).

31) Suchet, J.P., J. Phys. Ghem. Solids, 16, 265 (1960).

32) Collins, R.J., J. Appl. Phys., 30, 1135 (1959).

33) Hopfield, J.J., and D.G.Thomas, Phys. Rev., 122, 35 (1961).

34) Keyes, R.W., Phys. Rev., 99, 490 (1955).

35) Averkin, A.A., and P.G. Dermenzhi, Fiz. Tverd. Tela, 8, 103 (1966) ; English transl. : Soviet Phys.Solid State, 8, 79 (1966).

36) Paul, W., "High Pressure Physics and Chemistry”, R.S. Bradley ed., p. 299 (1963) Academic Press, London.

37) Hannay, N.B., "Semiconductors", N.B. Hannay ed., p. 1 (1959) Reinhold Publishing Co., New York.

38) Mott, N.F., and R.W. Gurney, "Electronic Processes in Ionic Crystals", 2nd ed., p. 68 (1950) Clarendon Press, Oxford. 